\title{
A 6-month-old boy presented with progressive jaundice, dark urine and generalized pruritus for one month
}

\author{
Hazera Akter, Md. Wahiduzzaman Mojumder, A. S. M. Bazlul Karim, Mohammed Kamal, \\ Kamrun Nahar and Md. Benzamin
}

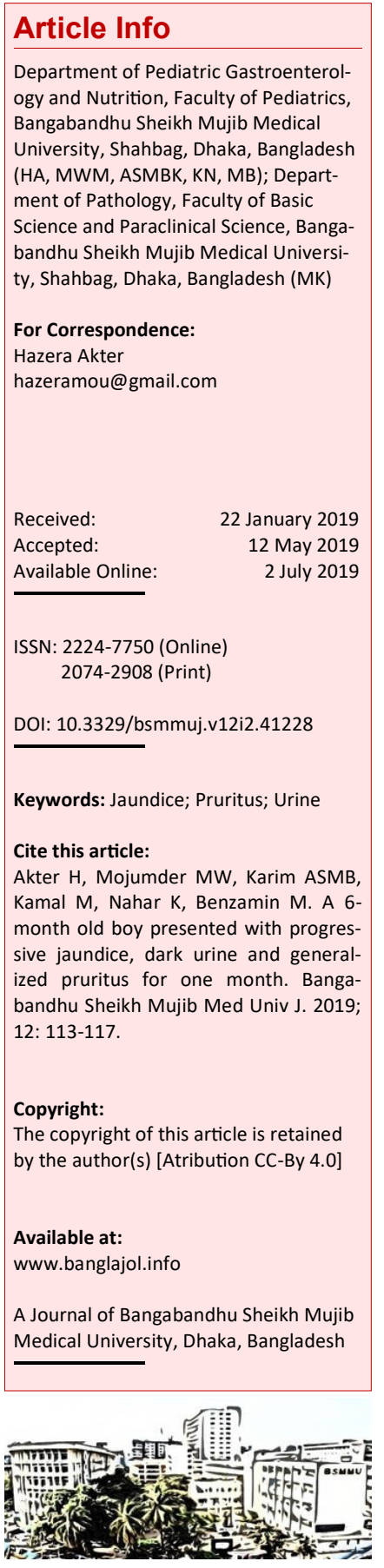

\section{Presentation of Case}

Dr. Hazera Akter: A 6-month-old boy of nonconsanguineous parents admitted to the Department of Pediatric Gastroenterology with the complaints of progressive jaundice, dark urine and generalized pruritus for one month (Figure 1). The boy was well up to five months of age. Then he developed jaundice which was progressive in nature with intermittent pale colored stool along with dark urine. His mother also complaints for generalized pruritus which was severe in intensity (disturbing sleep and daily activities) without any diurnal variations. There was no history of sib death or family history of a similar type of illness.

Physical examination revealed he was moderately icteric, scratch mark present over the whole body and mild $(2 \mathrm{~cm})$ firm hepatomegaly present with normal physical development.

The laboratory data included normal complete blood counts except leucocytosis mostly lymphocyte. Serum total bilirubin was $8.8 \mathrm{mg} / \mathrm{dL}$ (conjugated bilirubin $5.1 \mathrm{mg} / \mathrm{dL}$ ), alanine transaminase $26 \mathrm{U} / \mathrm{L}$ and gamma-glutamyl transferase $22 \mathrm{U} / \mathrm{L}$, prothrombin time, activated partial thromboplastin time and international normalized ratio were within normal limit. Serum cholesterol level was 133 mg/dL. Anti-HAV IgM was negative. Urine R/E was normal and urinary reducing substances were nil. Renal functions, X-ray spines and echo-

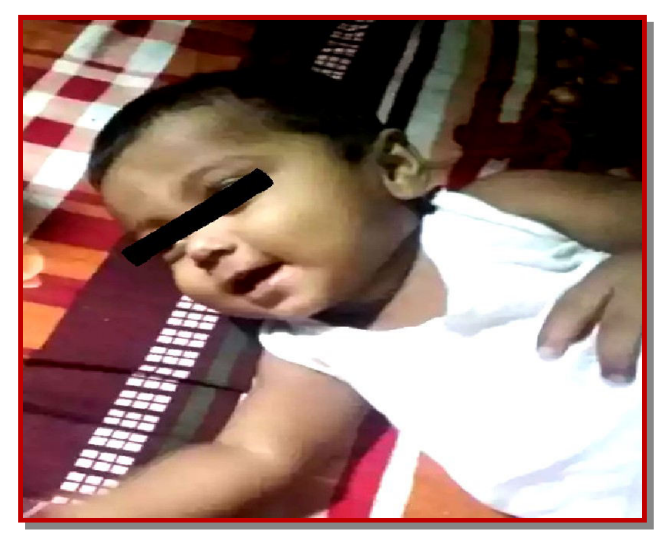

Figure 1: Our patient cardiography were normal. Ultrasonography of the abdomen showed mild hepatomegaly. Slit lamp examination of eyes showed no abnormality. Liver biopsy was done and histopathological examination revealed the paucity of interlobular bile ducts (out of eight portal tracts examined, two had bile duct) (Figure 2A and B). Bile duct to portal tract ratio was 0.25 . The hepatocytes were mildly swollen and occasional sinusoid contained bile plugs.

Based on history, physical findings and laboratory investigations with liver biopsy our diagnosis was nonsyndromic interlobular bile duct paucity.

\section{Provisional Diagnosis}

Nonsyndromic bile duct paucity

\section{Differential Diagnosis}

Dr. A. S. M. Bazlul Karim: The differential diagnoses were the following:

\section{Alagille syndrome}

Alagille syndrome is an autosomal dominant, multisystem developmental disorder. It is a familial disease with wide variability in its clinical presentation. Majority of the patients present before six months of age with jaundice and failure to thrive or cardiovascular symptoms. Cholestasis is manifested by jaundice and pruritus, present in $96 \%$ of cases. Jaundice presents as a conjugated hyperbilirubinemia in the neonatal period and the magnitude of the hyperbilirubinemia is minor compared to the degree of cholestasis. Severe cholestasis results in the formation of xanthomas, especially on the extensor surfaces of the fingers, the palmar creases, nape of the neck, popliteal fossa, buttocks, and around inguinal trauma sites. These lesions are persisting but may gradually disappear after 10 years of age. The presence of interlobular bile duct paucity and at least 3 of 5 clinical features are necessary for the diagnosis: Chronic cholestasis, cardiac disease, ocular 


\begin{tabular}{|c|c|c|}
\hline \multicolumn{3}{|c|}{ Table I } \\
\hline \multicolumn{3}{|c|}{ Investigation reports of patient } \\
\hline Parameters & Findings & References \\
\hline Hemoglobin (g/dL) & 11.3 & 13.5 \\
\hline $\begin{array}{l}\text { Total leukocyte count (cells/ } \\
\mathrm{cmm} \text { ) }\end{array}$ & 13,000 & $4,000-10,000$ \\
\hline \multicolumn{3}{|l|}{ Differentials } \\
\hline Lymphocyte (\%) & 54 & $40-75$ \\
\hline Neutrophil (\%) & 39 & $20-50$ \\
\hline Eosinophil (\%) & 05 & $1-6$ \\
\hline Monocyte (\%) & 02 & $2-10$ \\
\hline Platelet count & $270 \mathrm{~K} / \mathrm{L}$ & $150-400 \mathrm{~K} / \mathrm{L}$ \\
\hline Total Bilirubin (mg/dL) & 8.8 & $0.2-1.1$ \\
\hline Conjugated bilirubin (mg/dL) & 5.1 & \\
\hline Serum ALT (mg/dL) & 26 & $20-60$ \\
\hline $\begin{array}{l}\text { Gamma-glutamyl- } \\
\text { transpeptidase (U/L) }\end{array}$ & 22 & $0-30$ \\
\hline Serum creatinine $(\mathrm{mg} / \mathrm{dL})$ & 0.85 & $0.4-1.4$ \\
\hline Prothombin time (sec) & 12.5 & $12-16$ \\
\hline INR & 1.04 & \\
\hline APTT (sec) & 30 & $20-40$ \\
\hline Serum cholesterol (mg/dL) & 133 & $<200$ \\
\hline Anti-HAV IgM & Negative & \\
\hline Urine $\mathrm{R} / \mathrm{M} / \mathrm{E}$ and $\mathrm{C} / \mathrm{S}$ & $\begin{array}{r}\text { Pus cell, RBC, mac- } \\
\text { rophage- Nil } \\
\text { Reducing sub- } \\
\text { stances- Nil }\end{array}$ & \\
\hline Stool examination & $\begin{array}{r}\text { No red blood cells } \\
\text { or leukocytes }\end{array}$ & \\
\hline
\end{tabular}

abnormalities, skeletal abnormalities, and characteristic facies. In infants, less than 6 months of age, when the bile duct paucity is usually absent, three or four clinical features should be adequate to make the diagnosis. In a family with one definite proband, other members with two and even one feature are suggestive to have Alagille syndrome.1-3

Dr. Akter: After evaluating patient's clinical presentations, the physical findings and investigations results, liver biopsy was done and send for histopathological examination. Histopathology report showed the paucity of interlobular bile ducts (out of eight portal tracts examined, two had bile duct and bile duct to portal tract ratio was $0.25 \mathrm{~cm}$. The hepatocytes were mildly swollen and occasional sinusoid contained bile plugs. The diagnosis was made based on the histopathologic examination of the liver. Clinical features described in Alagille syndrome were not present in our case except cholestasis which led us to a diagnosis of nonsyndromic interlobular bile duct paucity.

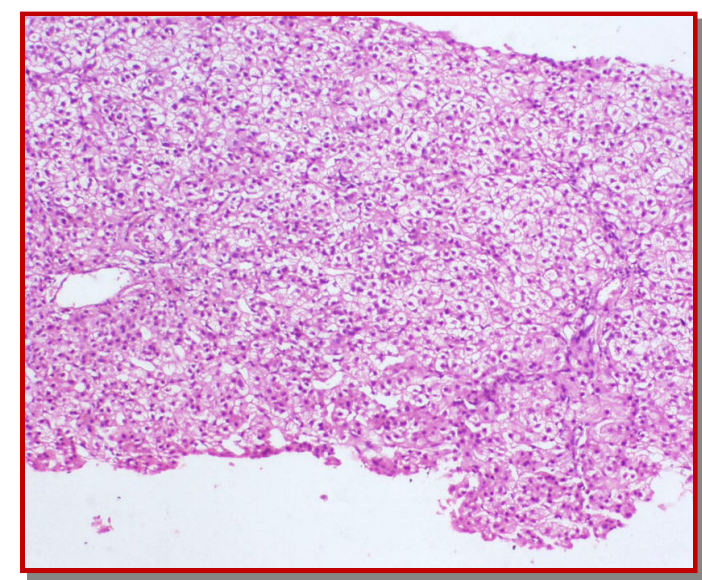

Figure 2: Liver biopsy of our patient showing portal tract without any bile duct (H \& E, x220)

\section{Dr. Hazera's Diagnosis}

\section{Nonsyndromic bile duct paucity}

Dr. Parisa Marjan: The patient presented with jaundice and pruritus. Why it is not a case of progressive familial intrahepatic cholestasis (PFIC)?

Dr. Akter: Progressive familial intrahepatic cholestasis is a clinical syndrome of intrahepatic cholestasis which presents in infancy or early childhood. PFIC1 and PFIC2 usually present symptoms within the first 3 months of life and PFIC3 present at early adulthood whereas our patient presented at 5 months of his age. Along with cholestasis patients with PFIC1 can present with deafness, pancreatic insufficiency, cholelithiasis, and diarrhea. These features were not present in our case. Serum gamma-glutamyltranspeptidase activity is elevated in PFIC3 but in our case it was normal. Progressive familial intrahepatic cholestasis usually runs in families, which was not so in our case. For these reasons the possibility of progressive familial intrahepatic cholestasis is ruled out. $\underline{4-8}$

Dr. Archana Shrestha Yadav: Have you put biliary atresia at your differential diagnosis?

Dr. Akter: No. Biliary atresia can also present with jaundice with pruritus but it commonly present in the neonatal period with persistent pale stool. Our patient presented with jaundice, pruritus, intermittent pale stool and hepatomegaly at his $5^{\text {th }}$ months. The typical histopathological findings of biliary atresia are inflammation, portal tract fibrosis, cholestasis, and bile duct proliferation which were also absent in our case. 2

Dr. Suborna Rani Das: How will you differentiate between the syndromic and nonsyndromic paucity of bile duct?

Dr. Kamrun Nahar: Paucity of intralobular bile ducts 
is a histological diagnosis. Two types are recognized: Syndromic and nonsyndromic. The syndromic form is called Alagille syndrome which is diagnosed by the presence of at least three of five major features: Chronic cholestasis (jaundice, pruritus, xanthoma), cardiac disease (pulmonary artery stenosis, tetralogy of Fallot, patent ductus arteriosus, ventricular septal defect and pulmonary atresia), ocular abnormalities (posterior embryotoxin), skeletal abnormalities (sagittal cleft or butterfly vertebrae), and characteristic (facies prominent forehead, moderate hypertelorism with deep set eyes, a small pointed chin, and a saddle or straight nose) along with paucity of intralobular bile ducts. The later one nonsyndromic bile duct paucity is associated with congenital infections with cytomegalovirus and rubella, metabolic disorders, endocrine disorders, chromosomal defects (Trisomy 17, 18 and 21), immunologic disorders, altered bile acid metabolism and chronic rejection of transplants. If no cause is identified it is called idiopathic nonsyndromic bile duct paucity.., 9

Dr. Saidul Islam Sumon: How did you confirm the diagnosis?

Dr. Nahar: Currently there is no clinical, biochemical or radiological test specific for nonsyndromic paucity. Diagnosis is based solely on the clinical phenotype and histopathological findings of the liver. The bile duct paucity is identical in the nonsyndromic form.?

Dr. Mohuya Mondal: Should you do genetic analysis for diagnosis of this patient?

Dr. Nahar: Genetic analysis can help in exclusion of alagille syndrome and give information about the presence of any chromosomal abnormalities like trisomy. $\underline{18,21}$

Dr. Sayma Munmun: How you treated your patient?

Dr. Nahar: We gave a general treatment of pruritus including aggressive skin hydration with emolients and trimmed fingernails. We started ursodexycholic acid, antihistamine and fat-soluble vitamin supplementation along with exclusive breast feeding.

Dr. Subir Ananda Biswas: What are the other treatment options?

Dr. Akter: If the patient is nonresponsive to ursodeoxycholic acid, additional antipruritic agents including hydroxyzine, diphenhydramine, rifampin, naltrexone, and cholestyramine alone or in combination can be used. In children with severe pruritus surgical interventions, such as biliary diversion and ileal bypass has been shown to relieve symptoms but does not prevent the progression of liver disease. However, some recent study shows that omega-3 polyunsaturated fatty acid can be effective as a potent choleretic agent that leads to clinical improvement in children with nonsyndromic paucity. $\underline{10}$

Dr. Rana Kumar Biswas: When do you advise for liver transplantation?

Dr. Nahar: Patient with complications of end-stage liver disease and hepatocellular carcinoma are amenable to liver transplantation. Patients with paucity of intralobular bile ducts include intractable pruritus despite medical management which affects the quality of life, intractable failure to thrive despite enteric nutritional support, and osteodystrophy are also considered for liver transplantation. $\underline{10,11}$

Dr. Mondal: What is the prognosis of this patient?

Dr. Akter: The prognosis of nonsyndromic bile duct paucity is highly variable and the patient can be categorized into two groups according to their outcome: Those with progressive disease and those with a benign course. Evolution to cirrhosis of the liver in infancy is infrequent but higher than in the cases of syndromic paucity..$\underline{12,13}$

\section{Discussion}

Dr. Wahiduzzaman Mazumder: Cholestasis refers to the consequences of reduction or interruption of the bile flow or its constituents at any level from hepatocyte to the duodenum and is defined serologically as prolonged conjugated hyperbilirubinemia. It is classified as extrahepatic and intrahepatic in causes. Intrahepatic cholestasis may results from the defective mechanism of bile formation due to bacterial, protozoal and viral infections, also may have a metabolic or toxic origin. It also can be secondary to an abnormality of biliary secretion as a result of hepatocyte dysfunction or abnormal excretion of bile. The paucity of intrahepatic bile ducts can cause cholestasis which comprises about $6.7 \%$ of the causes of intrahepatic cholestasis. $1,14,15$

Bile duct paucity is defined as the absence or marked reduction in the number of interlobular bile ducts within portal tracts. It is a significant abnormality causing intrahepatic cholestasis in children. 2 $\underline{4,12}$ Histopathologically, it is expressed as the ratio of the number of interlobular bile ducts to the number of portal tracts. In normal children, this ratio is 0.9 to 1.8 and a ratio $<0.5,0.6$, or 0.9 is considered hypoplasia or the paucity of intralobular bile duct in the pediatric age group. Although the etiopathogenesis is not clear, three theories have been proposed for ductal paucity: Congenital absence of bile ducts, partial atrophy or primary duct destruction. It is an important problem that is faced commonly in the pediatric age group.

Clinically the paucity of intrahepatic bile ducts is classified as syndromic (which is called Alagille syndrome), or nonsyndromic. 1 The nonsyndromic 
bile duct paucity which is seen rarely may idiopathic or can be associated with congenital infections (cytomegalovirus, rubella) metabolic disorders (alpha-1 antitrypsin deficiency, cystic fibrosis Niemann-Pick type C, Zellweger syndrome), nutriational (total parenteral nutrition), endocrine disorders (hypopituitarism), chromosomal defects (Trisomy 17, 18 and 21), immunologic disorders, altered bile acid metabolism and chronic rejection of transplants. $\underline{16-20}$

Alagille syndrome or arteriohepatic dysplasia is diagnosed on the basis of interlobular bile ductular paucity in the liver histology with any three of five major features such as cholestatic liver disease, consistent cardiac disease, skeletal abnormalities (butterfly vertebrae), ocular abnormalities (posterior embryotoxon) and a characteristic Alagille (triangular) facies. 5 In features of Alagille syndrome in 92 patients, Emerick et al. (1999) described interlobular bile ductular paucity in $85 \%$, cholestatic jaundice in $96 \%$, cardiac anomalies in $97 \%$, characteristic triangular facies in $96 \%$ cases, vertebral defects (butterfly vertebra) in $51 \%$ and posterior embryotoxon in the eye in 78\%.21 Kamath et al. (2012) described renal tubular acidosis, tubulointerstitial nephropathy: $40 \%$, pancreatic insufficiency, cerebrovascular system anomalies with moyamoya vascular pattern, intracranial aneurisms (carotid and basilar arteries): $14 \% . \underline{.22-23}$

Our patient presented with cholestasis in the form of jaundice, pruritus, intermittent pale stool and hepatomegaly. Cholestatic jaundice in infancy is an important clinical condition. There are over a hundred specific causes of neonatal cholestasis, among these causes neonatal hepatitis, extrahepatic biliary atresia and choledochal cysts are more common. $\underline{13}$ The paucity of interlobular bile ducts is a rare cause of intrahepatic cholestasis in infancy. So, it should be considered if infant present with cholestasis and its differentiation from extrahepatic causes of cholestasis is important in order to avoid surgery.

In nonsyndromic bile duct paucity, there is no specific clinical, biochemical or radiological test and diagnosis is based on the bile duct pathology and the clinical phenotype. Bile duct paucity can be defined only histologically and requires a sufficient large liver biopsy that contains at least five portal tracts.10 Some authors mentioned eight portal tracts and some researchers mentioned 10 portal tracts are needed for the diagnosis. The diagnosis of our patient was based on histopathological evaluation of the liver tissue. In our patient, eight portal tracts were identified among these only two had bile ducts, bile duct to portal tract ratio was 0.25. Clinical features of Alagille syndrome was not present in our case except cholestasis which led us to a diagnosis of nonsyndromic bile duct paucity. This is seen more rarely and there are only a few reports in our country about this disease. $\underline{.24-26}$

The mainstay of treatment is symptomatic relief of pruritus, optimization of nutritional status, and management of complications of chronic liver disease. All the infants and children who presented with cholestasis were treated with fat-soluble vitamins. Ursodeoxycholic acid has been used for the management of pruritus as it stimulates bile flow by increased liquidity of bile. Additional antipruritic medications including hydroxyzine, diphenhydramine, rifampin, naltrexone, and cholestyramine alone or in combination may also be used. Newer study shows that omega-3 polyunsaturated fatty acid can be effective as a potent choleretic agent for children with nonsyndromic paucity. If the medical treatment failed to relief prutitis, surgical interventions such as biliary diversion and ileal bypass have been done. Liver transplantation should be done in patients with complications of end-stage liver disease and hepatocellular carcinoma, intractable and refractory pruritus despite medical management. $\underline{10,11}$

The prognosis of nonsydromic bile duct paucity is highly variable. The patient can be separated into two groups according to their outcome: Those with progressive disease and those with a benign course. 21 Progression to cirrhosis has been reported to occur in $45 \%$ of patients while in patients with Alagille syndrome it is seen in only $14 \%$ of cases. $\underline{28}$ The syndromic form shows clinical and biochemical improvement whereas development of cirrhosis is common in the nonsyndromic form. 4 However, complete clinical and histopathological resolution are also described in nonsyndromic form. Berezin et al (1995) 29 reported a neonate with nonsydromic bile duct paucity in whom biochemical resolution occurred at 5 years of age, development of normal bile duct also seen in this case. Kansu et al (1998) $\underline{12}$ reported a 2 months old infant and a 20 days old neonate with nonsydromic bile duct paucity, clinical and biochemical resolution were seen in both patients about six months after diagnosis. The $2^{\text {nd }}$ one shows histological improvement after 18 month but $1^{\text {st }}$ one doesn't show histological improvement even after 2 years.

\section{Follow-up}

Our patient improved clinically and the biochemical resolution was seen about 1 year after diagnosis but repeat liver biopsy cannot be performed.

\section{Final Diagnosis}

Nonsyndromic bile duct paucity 


\section{Conflict of Interest}

The authors declare no conflict of interest.

\section{References}

1. Alves De Tommaso AM, Kawasaki AS, Hessel G. Paucity of intrahepatic bile ducts in infancy: Experi -ence of a tertiary center. J Ped Gastroenterol. 2004; 41: 190-92.

2. Figiel SC, Franco A, Pucar D, Lewis KN, Lee JR. Paucity of biliary ducts: A rare etiology of neonatal cholestasis. J Radiol Case Rep. 2012; 6: 29-38.

3. Kamath BM, Piccoli DA. Heritable disorders of the bile ducts. Gastroenterol Clin N Am. 2003; 32: 85775 .

4. Baker A, Kerkar N, Todorova L, Kamath BM, Houwen RHJ. Systematic review of progressive familial intrahepatic cholestasis. Clin Res Hepatol Gastroenterol. 2019; 43; 20-36.

5. Srivastava A. Progressive familial intrahepatic cholestasis. J Clin Exp Hepatol. 2014; 4: 25-36.

6. Bull LN, Thompson RJ. Progressive familial intrahepatic cholestasis. Clin Liver Dis. 2018; 22: 657-69.

7. Agarwal S, Lal BB, Rawat D, Rastogi A, Bharathy KG, Alam S. Progressive familial intrahepatic cholestasis (pfic) in Indian children: Clinical spectrum and outcome. J Clin Exp Hepatol. 2016; 6: 203-08.

8. Jacquemin E. Progressive familial intrahepatic cholestasis. Clin Res Hepatol Gastroenterol. 2012; 36: S26-S35.

9. Meena BL, Khanna R, Bihari C, Rastogi A, Rawat D, Alam S. Bile duct paucity in childhood-spectrum, profile, and outcome. Eur J Pediatr. 2018; 177: 126169

10. Verkade HJ, Sturm E. Walker's Pediatric gastrointestinal disease. $6^{\text {th }}$ ed. North Carolina, People's Medical Publishing House, 2018, pp 1192-204.

11. Mozhgan Z, Bita G, Mahmood H, Hajar E. Paucity of intrahepatic bile ducts in neonates: The first case series from Iran. Iran J Pediatr. 2013; 23: 65-70.

12. Kansu A, Doganci T, Erden E, Girgin N. Nonsyndromic paucity of interlobular bile ducts: Two children with a benign course. Turkish J Gastroenterol. 1998; 2: 198-200.

13. Pereda T, Gavila F. Hereditary nonsyndromic paucity of intrahepatic bile ducts as an indication for liver transplantation. Transplant Proc. 2003: 35; 719-20.

14. Reau NS, Jensen DM. Vanishing bile duct syndrome. Clin Liver Dis. 2008; 12: 203-17.

15. Suchy FJ, Sokol RJ, Balistreri WF. Liver disease in children. $4^{\text {th }}$ ed. Cambridge University Press, 2014, pp 199-233.

16. De Bruyne R, Van Biervliet S, Velde SV, Van Winckel M. Clinical practice: Neonatal cholestasis. Eur J Pediatr 2011; 170: 279-84.

17. Yamaguti DC, Patricio FR Morphometrical and immunohistochemical study of intrahepatic bile ducts in biliary atresia. Eur J Gastroenterol Hepatol. 2011; 23: 759-65.

18. Yehezkely-Schildkraut V, Munichor M, Mandel $\mathrm{H}_{\text {, }}$ Berkowitz D,Hartman C, Eshach-Adiv O, Shamir R. Nonsyndromic paucity of interlobular bile ducts: Report of 10 patients. J Pediatr Gastroenterol Nutr. 2013; 37: 546-49.

19. Sergi C, Bahitham W, Al-Bahrani R. Bile duct paucity in infancy: Liver biopsy in modern medicine. Mizuguchi Y (ed). $1^{\text {st }}$ ed. In Tech, 2011, pp 295-304.

20. Chang $\mathrm{CH}$, Kim JH, Lee SJ, Lee DS, Kim DK, Choi SM, Kim WT,Jang TJ. A case of nonsyndromic paucity of interlobular bile ducts in Down Syndrome. Korean J Pediatr. 1999; 42: 858-62.

21. Emerick KM, Rand EB, Goldmuntz E, Krantz ID, Spinner NB, Piccoli DA. Features of Alagille syndrome in 92 patients: Frequency and relation to prognosis. Hepatology 1999; 29: 822-29.

22. Kamath BM, Podkameni G, Hutchinson AL, Leonard LD, Gerfen J, Krantz ID, Piccoli DA, Spinner NB, Loomes KM, Meyers K. Renal anomalies in Alagille syndrome: A disease-defining feature. Am J Med Genet A. 2012; 158A: 85-89.

23. Alam R, Rukunuzzaman M, Karim ASMB, Hossen $\mathrm{K}$, Yasmin A. Alagille syndrome with moyamoya disease. Bangabandhu Sheikh Mujib Med Univ J. 2017; 10: 166-68.

24. Mitchell E, Gilbert M, Loomes KM. Alagille Syndrome. Clin Liver Dis. 2018; 22: 625-41.

25. Earan SK, Ghildiyal RG, Sankhe P, Rathi PM, David J. Alagille syndrome: Syndromic paucity of bile ducts, a fully expressed syndrome. Bombay Hospital J. 2015; 2: 190-93.

26. Kumar S, Puri P, Gujral K. Intrahepatic cholestasis of pregnancy. Curr Med Res Pract. 2018; 8: 230-34.

27. Sathya P, Pushpanathan C. Nonsyndromic paucity of intrahepatic bile ducts. Paediatr Child Health. 2015; 6: 289-91.

28. Herman HK, Abramowsky CR, Caltharp S, Metry D, Cundiff CA, Romero R, Gillespie SE, Shehata BM. Identification of bile duct paucity in Alagille Syndrome: Using CK7 and EMA immunohistochemistry as a reliable panel for accurate diagnosis. J Pediatr Develop Pathol. 2016; 19: 47-50.

29. Berezin S, Beneck D, Altman P, Schwarz S. Resolution of nonsyndromic paucity of intrahepatic bile ducts in infancy. Dig Dis Sci. 1995; 40: 82-85. 